\title{
Study of energy-efficient architecture address utilizing topography and geomorphology based on Google Earth and its remote sensing data
}

\author{
Yijin Wang ${ }^{1, *}$ \\ ${ }^{1}$ Northeast Yucai school, Shenyang, China, 214191
}

\begin{abstract}
In this paper, we describe the formatting guidelines for ACM SIG Proceedings. With the development of social economy, smart cities, especially green energy-saving buildings, are foremost trend in the future. The location of green buildings has a very important impact on the design and plan of future smart cities. The influence of the natural environment, especially that of the topography and landform on the location of architectural design is very significant. Google Earth (GE) platform can provide sufficient remote sensing data, which greatly interpret and promote surface information. However, just few people have done related research. This article takes Beijing as an example and uses Google Earth platform and the remote sensing data to obtain the 3D digital elevation model (DEM) data; and then Google earth's geomorphology data are used to analyze the landform features. Finally, by analyzing their characteristics and distribution features, five energy-saving building locations were selected in Beijing. It can be concluded that GE, is an effective and potential platform for providing remote sensing data, and analyzing the DEM and landform. The rational analysis of the building addresses in this paper could help the buildings to avoid potential geological disasters and make full use of natural resources. Moreover, this research on energyefficient building addresses make a suggestion for future smart city planning.
\end{abstract}

\section{INTRODUCTION}

With the rapid economic development in recent years, people are increasingly concerned that the environment should not be the victim of economic development. Facing the current demand for energy saving and emission reduction, building smart cities, including green and energy-efficient buildings has become the main tendency. The reasonable choice of building addresses is a prerequisite for the long-term development of energy-saving buildings. To make sure that the buildings could make full use of natural resources and be far from the risks of future geological disasters, the surrounding geography and geomorphology should be studied and analyzed in detail because of their profound effect on the design and plan of the buildings.

Many scholars have researched this problem. Song and Zhang proposed the impact of landscape and climate factors on architectural design, and concluded that we should increase our understanding of the affinity of the ecological environment in modern architecture [2]. Butera et al. [1] once proposed that the architectural design should consider the coordination between the building and the surrounding environment. They concluded that reasonable and realistic building sites are important for people's life. The architecture not only affects people's life, but also has significant influence on the economic development and the city's construction $[2] ;[3]$.

In terms of the environment, saving energy remains a challenge for scholars because of its difficulties in collecting and handling big data sets. Moreover, natural environment has complex typical features under the impact of various conditions and its influence on the design of buildings is a serious problem for city development and people's life. Hence, it is imperative to develop more appropriate management control programs for government managers, provide comfortable housing service for people which requires information in a large scale [10]. The Google Earth (GE) is a cloud computing platform which was designed to store and process a large number of data (https://earthengine.google.com/datasets/) for analysis and final decision making. Many researches have demonstrated that GE platform is a quite effective method of dealing with huge data sets at different scales. The present archive of data includes most of the satellites data, as well as Geographic Information Systems (GIS) vector information and other demographic, digital elevation models (DEM), environment and climate data layers [9]. Therefore, based on the GE, scholars can utilize huge data, map trends, quantify resources, and multitude of methods to undertake quantitative analysis of global problems. Based on current researches, the project topics using GE can be divided into four major aspects: Vegetation

\footnotetext{
* Corresponding author: yijin_cici_wang@163.com
} 
Mapping and Monitoring, Landcover Mapping, Agricultural Applications, and Disaster Management and Earth Sciences [9]. For example, use GE, an ecosystem evaluation study in a Brazilian semi-arid landscape has demonstrated that it could produce a higher classification accuracy [6]. As for disasters, Liu et al. developed a flood prevention and response system using the cloud calculation-based GE platform [12]. With respect to these kinds of sustainable development and environment protection, however, its uptake and usage of the opportunity remains varied and unclear [9], in particular, research on the site selection of the energy-saving buildings based on GE is a blank and brand-new area.

Therefore, this paper use Google earth and its remote sensing data to analyze the 3D digital elevation model and the geomorphology characteristics and then select 5 suitable building addresses in Beijing. Firstly, data are obtained from Google earth platform and then 3D DEM was modeled by TIN, which could overcome the problem of data redundancy in higher matrices. Safety and energy-saving are taken into consideration to the site selection. This can provide a new insight about studying the site selection of the energy-efficient buildings and make suggestions for the government managers to make environmental protection policy.

\section{Method}

\subsection{DEM model}

In the modeling process, we use digital elevation model (DEM) to study the fluctuation of the ground. DEM are aerial or aerospace remote sensing images, topographic maps and ground measurement records. 3 dimensions are used to simulate the terrain, namely longitude, latitude and elevation. Firstly, the Triangulated Irregular Network is used based on the discrete data obtained from the SRTM network. And then all sampling points are connected (the vertices of each triangle) into mutually continuous triangular in accordance with the principle of optimal combination. TIN divides the area into a network of adjacent triangles. Any point in the area will fall within the vertex, line or triangle of the triangle. When the two vertices of the triangle are known, use the cosine theorem to calculate the size of the triangle's internal angle of the alternative third vertex, and select the point corresponding to the largest one as the third vertex of the triangle. Then all of the points are connected, to make sure each triangle is an acute triangle or the length of the three sides is approximately equal and finally form the Delaunay net. Because TIN can determine the density and location of sampling points according to the complexity of terrain, it can fully represent terrain feature points and lines, therefore reducing data redundancy in areas with flat terrain.

\subsection{Landform}

Landform is the general term for various forms of the earth's surface, and can also be called topography. The surface morphology is diverse, and the causes are also different. It is the result of the comprehensive effect of internal and external forces on the crust. It can provide a lot of information about the earth surface.

\section{Results and analysis}

\subsection{The study area and data}

This study takes Beijing as an example. Beijing is located at $115.7-117.4^{\circ}$ east longitude, $39.4-41.6^{\circ}$ north latitude, and the center is located at $39^{\circ} 54^{\prime} 20^{\prime \prime}$ north latitude, $116^{\circ} 25^{\prime} 29^{\prime \prime}$ east longitude, with a total area of 16410.54 square kilometers. It is mainly dominated by mountainous and plain topography, with high northwest and low southeast. It is worth noted that its landform is the expression of man-made landform. People have changed the original geomorphology through a large number of engineering and technical activities to develop the city and established a new urban landform system.

With respect to the topography and geomorphology, Google Earth and remote sensing data were utilized to show their characteristics. Google earth as the basic platform can intuitively observe the terrain and the land coverage. All of the remote sensing data provided by Google earth are higher spatial resolution and wide range in the areas. It is an effective to obtain the geography and geomorphology data.

\subsection{The topography features}

Using the modeling method mentioned in the second part (2.1), the DEM of Beijing is established and shown in the Figure 1. 


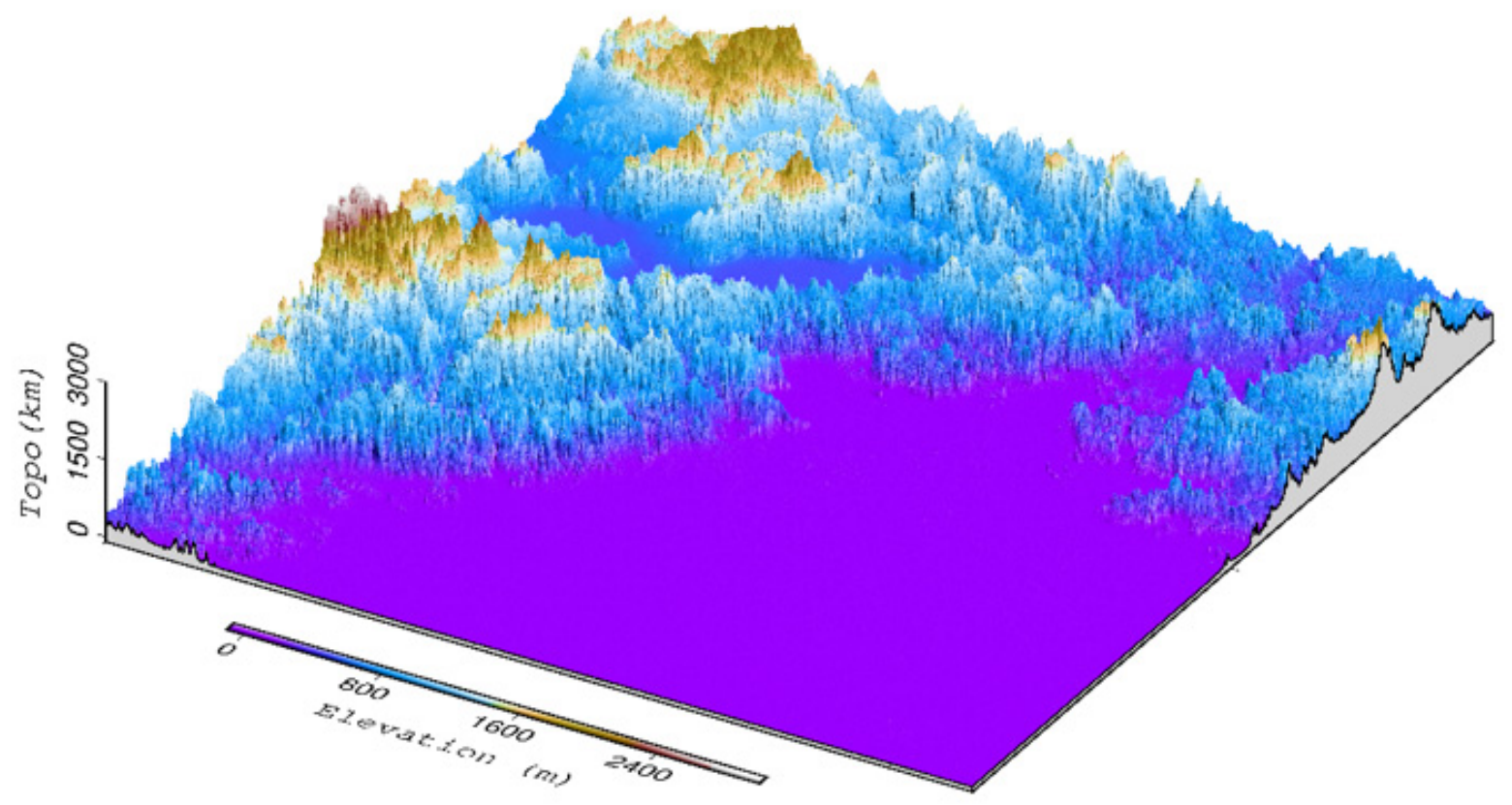

Figure 1. The DEM model of Beijing

As shown in Figure 1, the 3-dimensional (3D) topography in Beijing is mainly mountain in the northwest, and plains in the southeast and the central area. There is a higher risk of disasters, such as debris flows, landslide and mountain collapse in the northwest when selecting the buildings' location due to the proximity to the mountain. Moreover, buildings located at the foot of the mountain are not conducive to the use of natural resources such as sunlight. In contrast, sites in the southeast provide a safer environmental condition for the development of energy-efficient buildings.

\subsection{The geomorphology characteristics}

Geomorphology is important for buildings` site selection because of its complexity and variety. Beijing is a type of artificial landform (see Figure 2). Man-made landform is the general term that human beings shape on the earth surface. Human beings play an comprehensive, both constructive and destructive, role on the surface geomorphology of the earth. It has direct impacts in geomorphological processes and geomorphological types, as well as indirect influences in landform through various social activities, production, and scientific practices. This paper mainly describes this new urban geomorphology system by Figure 2 .

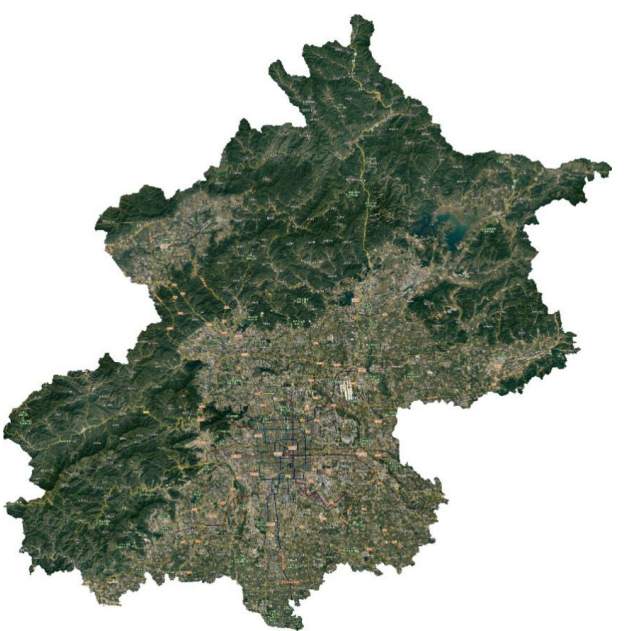

Figure 2. The landform of the Beijing (From Google Earth platform)

\subsection{Site selection of the energy-efficient buildings}

Based on the 3D DEM (see Figure 1) and the landcover in Beijing, five locations (see Figure 3) that are conducive to promoting energy-efficient buildings were selected. 


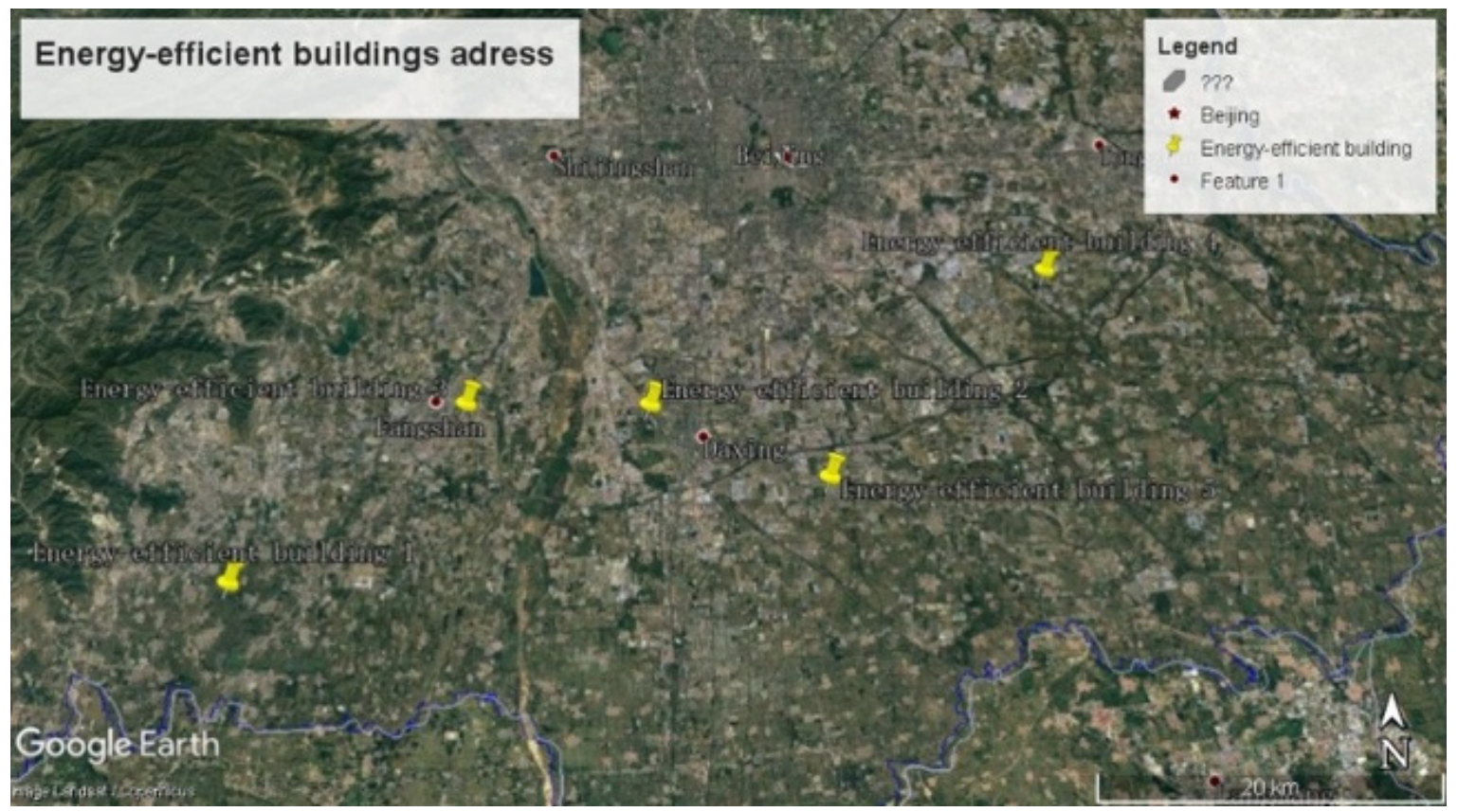

Figure 3. Five sites of the energy-efficient buildings in Beijing

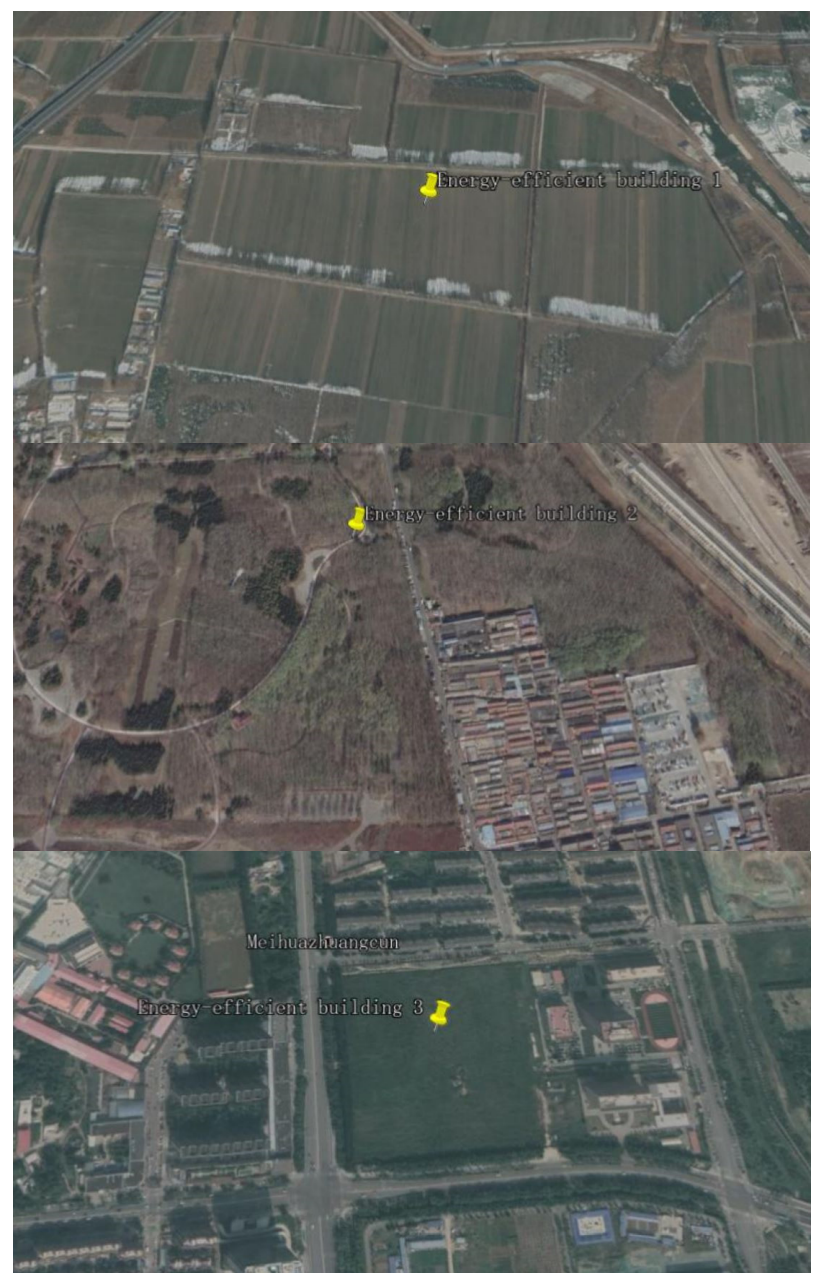

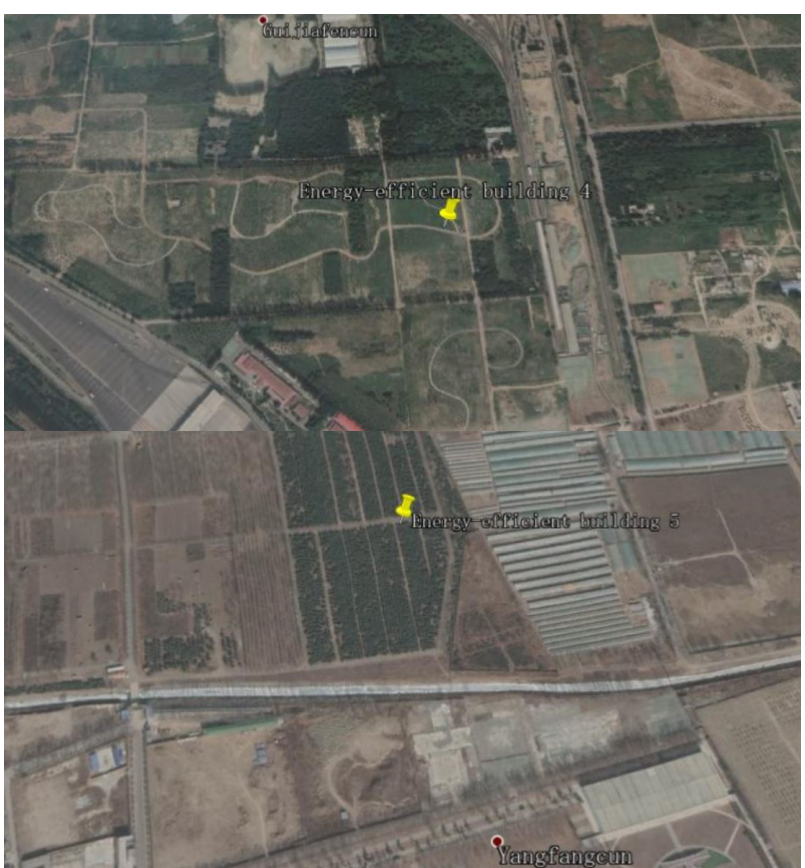

Figure 4. Five energy-saving building addresses and their surrounding land coverage

And the detailed sites and their surrounding environment are shown in the Figure 4. Firstly, to make full use of the sunlight and avoid the possible disasters caused by the mountains, all of the sites are chosen in the plain area. And secondly, to entertain the people's life, these sites are in the dense vegetation cover areas because beautiful natural surroundings, especially green plants contribute to physical and mental health.

\section{Conclusions}

To meet the requirement of saving energy and protecting the environment, buildings location should firstly achieve a harmonious relationship with the environment and improves their thermal efficiency. As the natural 
environment, especially the topography and landform, has a very important influence on architectural design. This paper uses the Google Earth platform and extracts the terrain data in Beijing to build a 3D model. Its topography is characterized by mountains in the northwest and plains in the southeast and center. And then the characteristics of the geomorphology are analyzed and it can be shown that the vegetation coverage is low because of the human influence and the buildings are densely distributed in the plain area. The location of the buildings has a major impact on the humanities of the building, people's life and economic development. Reasonable location of energy-saving buildings enhances the characteristics of building livability. According to this study, taking the topography and geomorphology into consideration, it can be concluded that the Beijing area could build green and energy-efficient buildings in the southeast and central areas. Faced with the shortage of resources and environmental pollution, these location selections could make constructive suggestions for the government managers to make full use of the natural resources and then provide new insights about architectural design and smart city plan in the future. Importantly, GE is an effective and potential tool to study the terrain and landform and can provide big data of the remote sensing. Utilizing it into the architectural design and plan, such as selection of building addresses, is a new insight to architect and responding scholars.

\section{References}

1. Butera F, Ferrari S, Aste N, et al. Ecological Design Procedures for Sino-Italian Environment and Energy Building : Results of the Ist Phase on Shape Analysis[C]// PLEA 2003 - The 20th Conference on Passive and Low Energy Architecture, 2003.

2. Lihong Song and Shengnan Zhang. Theoretical and Empirical Study on the Relationship between Urbanization and Economic Growth in China [J]. Journal of Industrial Technological Economics, 2014-03.

3. Xinchang Zhang, Junjun Kang, Qingnian Zhang. (2017). Urban Geographic Information System, Science Press, Beijing.

4. Zhiyong Zhang,Lianqing Li. (2012). A Dynamic analysis of the Interactive Effect between Economic Growth and Urbanization Rate-Based on the Data in 1986-2009 in Shandong Province[J]. Journal of Shandong University of Finance, 2012,Shangdong, China.

5. Yinfeng $\mathrm{Xu}$, Degen Wang, Mengyu Sha. Morphological Evolution and Influence Mechanism of Suzhou Urban Space from the Perspective of Double Dimension[J]. Ecomonic Geography, 2019, 039(004):75-84.

6. Goldblatt, R.; Rivera Ballesteros, A.; Burney, J. High Spatial Resolution Visual Band Imagery Outperforms Medium Resolution Spectral Imagery for Ecosystem Assessment in the Semi-Arid Brazilian Sertão. Remote Sens. 2017, 9, 1336.

7. Hao Binfei, Han Xujun, Ma Mingguo, et al., Research progress on the application of Google Earth Engine in geoscience and environmental science [J]. Remote Sensing Technology and Applicatio, 2018, 33(4):600-611. doi:10.11873/j.issn.1004-0323.2018.4.0600.

8. Lalit Kumar and Onisimo Mutanga. Google Earth Engine Applications Since Inception:Usage, Trends, and Potential [J]. Remote Sens. 2018, 10, 1509; doi:10.3390/rs10101509.

9. Onisimo Mutanga and Lalit Kumar. Google Earth Engine Applications [J]. Remote Sens. 2019, 11, 591; doi:10.3390/rs11050591.

10. Mao H , Xu X H . Research on Second Ring Expressway Traffic Congestion in Beijing[J]. Applied Mechanics and Materials, 2013, 409410:1339-1342.

11. Google Earth User`s Guide (2019). https://developers.google.com/earth-engine/tutorials

12. Liu, C.-C.; Shieh, M.-C.; Ke, M.-S.; Wang, K.-H. Flood Prevention and Emergency Response System Powered by Google Earth Engine. Remote Sens. 2018, 10, 1283. 